\title{
Coupled Damage and Plasticity Modelling in Transient Dynamic Analysis of Concrete
}

\author{
F. Gatuingt* And G. Pijaudier-Cabot* \\ *LMT-Cachan (ENS Cachan/CNRS/Université Paris 6/PRES UniverSud Paris), France
}

\begin{abstract}
In a concrete structure subjected to an explosion, for example a concrete slab, the material is subjected to various states of stress which lead to as many mode of rupture. Close to the explosive, a state of strong hydrostatic compression is observed. This state of stress produces an irreversible compaction of the material. Away from the zone of explosion, confinement decreases and the material undergoes compression with a state of stress, which is slightly triaxial. Finally, the compression wave can be reflected on a free surface and becomes a tensile wave, which by interaction with the compression wave, produces scabbing. We present in this paper a model aimed at describing these three failure modes. It is based on visco-plasticity and rate dependent damage in which a homogenisation method is used in order to include the variation of the material porosity due to compaction. The model predictions are compared with several experiments performed on the same concrete. Computations of split Hopkinson tests on confined concrete, a tensile test with scabbing, and an explosion on a concrete slab are presented.
\end{abstract}

\section{INTRODUCTION}

Modelling of concrete structures subjected to dynamic loading such as explosions, impacts and perforations is very demanding, both from the point of view of computer codes and from the point of view of material modelling. As far as computer codes are concerned, the major difficulties deal with a fast integration of the equation of motion (compatible with large three dimensional modelling), contact modelling in dynamics and in the case of perforation, the evolution of the concrete structure boundaries and large deformations. Explicit time integration, reduced spatial integration with hourglass control, specialised contact algorithms and adaptive meshing or erosive techniques exist nowadays in computer codes (such as LS-DYNA3D, ABAQUS and others). With such techniques, which for sure could be improved, it is possible to carry out, with a large but still reasonable amount of computer time, three dimensional computations of concrete structures in dynamics.

It seems, however, that constitutive modelling of concrete has not reached the same level of sophistication as computer methods. Most approaches are inspired by existing constitutive relations for alloys and ceramics, where a split between the spherical and deviatoric parts of the stress-strain relations is assumed (see e.g. [27, 16]). The deviatoric part is modelled with a plasticity-based, or viscoplastic model while the spherical part, also called "equation of state", is fitted with a cap model [19]. In the present paper, which is a sequel of recent research efforts carried out at LMT-Cachan [7, 6], we present a new constitutive relation for concrete in dynamics based on viscoplasticity combined with rate dependent continuum damage. This relation is restricted to cases with moderate strain rates in 
concrete, corresponding typically to explosions and impacts of projectiles at a velocity less than 350 $\mathrm{m} / \mathrm{s}$, yielding a hydrostatic pressure in the material which is less than $1 \mathrm{GPa}$.

The constitutive relation is detailed in section two. Three mechanisms will be combined: compaction which is modelled with a homogenisation technique, tensile damage which is described with a rate dependent damage model, and compression failure which is modelled with viscoplasticity combined to damage. Section three presents several examples of computations of laboratory tests (Split Hopkinson tests, dynamic tension tests) and of a concrete slab subjected to an explosion.

\section{CONSTITUTIVE EQUATIONS}

Let us consider the schematic case of an impact on a concrete slab depicted on Fig. 1 and look at the various modes of deformation and failure in concrete. Near the striker, inertial forces in concrete are such that the material is confined. Concrete experiences a very high state of triaxial compression. In statics, the response of concrete for such a state of stress has been characterised experimentally $[2,6]$. The equation of state, (e.g. the curve relating the volumetric deformation to the hydrostatic stress), exhibits an increase of the tangent and secant volumetric moduli with residual plastic strains upon unloading. Recently Gary et al. [13] obtained similar results in dynamics and observed a substantial rate effect. The hydrostatic stress at a given volumetric strain increases with the strain rate. Although the physical mechanisms responsible for the rate effect are not clearly explained at the moment (it might be due to intersticial water trapped in the porous microstructure of the material), it is generally accepted that the hardening shape of the equation of state is due to irreversible material compaction at a given strain rate.

Farther from the impactor, concrete is subjected to compression with a moderate amount of confinement. Its response is essentially controlled by microcracking in compression and internal friction. This state of stress can be captured by constitutive relations based on plasticity or plasticity coupled to damage $[12,28]$. Two characteristics of the material response ought to be recalled:

- The coupling between the volumetric and deviatoric responses of concrete has been experimentally demonstrated by Burlion et al. [6], by comparing hydrostatic and uniaxial tests on confined specimens.

- In uniaxial compression, it has been demonstrated with three dimensional computations that rate effects are very small compared to the confinement generated by inertial forces which are opposite to the lateral expansion of the specimen during loading [10, 14] (see Fig. 2a). The increase of the material strength, which is classically observed (see e.g. Ref. [4]) can be almost totally explained (in the range of strain rates considered in this paper) by such a transient confinement.

The third failure mechanism is scabbing and occurs on the back of the impacted structure. It is due to the interaction between the compressive wave generated by the impactor and the free surface. The compression wave is transformed into a tensile wave which might produce tensile cracking if the material strength is reached. This failure mechanism is rate dependent. Contrary to compression, inertial forces in uniaxial tension induce a three dimensional state of tensile stresses in the material (Fig. 2b) and cannot contribute to an increase of apparent strength. The response of the material in tension can be captured with a rate dependent damage model $[11,24]$ or a rate dependent smeared crack model [26]. 
An accurate description of the response of concrete subjected to impacts and explosions requires at least the combination of the above three features. For instance, scabbing is controlled by the material tensile strength and by the wave speed in the material which increases with compaction. During perforation, a large amount of energy can be dissipated. The consequences on tunelling, scabbing and on the output speed of the impactor after perforation can be important. Most constitutive relations implemented in existing computer codes are not entirely satisfactory because they do not account for the interaction between the deviatoric response of the material and its volumetric response and they hardly combine the above three mechanisms.

Bazant and co-workers have used the microplane approach for such a combination [3]. This microplane model has been implemented in a large scale computation code which includes finite strain description (not intended in the present paper). Note that the rate effect on the equation of state is not considered in the microplane model. Burlion et al. [7] proposed a coupled damage-plasticity model in which compaction and tensile cracking are combined into a single damage variable, which has the merit of being quite simple. It was however delicate to obtain a good description of uniaxial compression with such a model, which did not include strain rate effects too.

The constitutive relations presented in this paper are an extension of this model, aimed at a more accurate description of the material response, with a moderate degree of complexity. These relations are based on three main characteristics:

- The variation of porosity of concrete, which remains lower than $30 \%$, is taken into account with the help of a homogenisation technique. The method due to Mori-Tanaka is selected because it provides explicit expressions of the shear and bulk moduli of (uncracked) concrete. Thus, the elastic properties of material are functions of the variation of porosity, especially during hydrostatic compaction.

- Microcracking is captured with a rate dependent damage model [11], which uses two damage variables in order to provide a realistic response of the material in uniaxial compression while preserving a good description of tension, which is a characteristic of damage models. Rate effects are necessary in order to represent dynamic experiments (mostly dynamic tensile tests). In addition, rate dependency preserves well posedness of the equations of motion when strain softening occurs [25].

- In order to describe the material response in triaxial compression, a viscoplastic model is implemented, based on Perzyna's approach associated to a modified Gurson's yield function [20]. This yield function was already used by Burlion et al. [7] in order to introduce the coupling between the spherical and deviatoric response of the material on the growth of plastic strains. Rate effects are necessary in order to capture the increase of stress with strain rate in hydrostatic compression observed experimentally in dynamics [14].

\subsection{Damage model}

The relation between the stress $\sigma_{i j}$ and the reversible strains $\varepsilon_{i j}^{e}$ is:

$$
\sigma_{i j}=(1-D)\left[K \varepsilon_{k k}^{e} \delta_{i j}+2 G\left(\varepsilon_{i j}^{e}-\frac{1}{3} \varepsilon_{k k}^{e} \delta_{i j}\right)\right]
$$

where $K$ and $G$ are the bulk and shear moduli of concrete respectively. These moduli are assumed to remain constant in this section. Their variation, due to material compaction will be introduced later. 
We use the formulation due to Mazars which combines compression damage and tension damage [22]. The combination of these two types of damage is:

$$
D=\alpha_{c} D_{c}+\alpha_{t} D_{t}
$$

where $D_{c}$ and $D_{t}$ represent the compressive and tensile damage respectively, while $\alpha_{c}$ and $\alpha_{t}$ are parameters defined as:

$$
\begin{cases}\text { uniaxial tension } & \alpha_{c}=0 \\ \text { uniaxial compression } & \alpha_{t}=0 \\ \text { general loading } & \alpha_{t}+\alpha_{c}=1\end{cases}
$$

The definition of these parameters is given in the original work of Mazars [21, 22]. The growth of the two damage variables is governed by the elastic equivalent strain [22]:

$$
\tilde{\varepsilon}^{e}=\sqrt{\sum_{i}\left(\left\langle\varepsilon_{i}^{e}\right\rangle^{+}\right)^{2}}
$$

where $\varepsilon_{i}^{e}$ is the ith component of the tensor of the principal strains and $\langle x\rangle^{+}$is the positive part of $x$.

The growth of $D_{c}$ and $D_{t}$ is defined by the following equations which are similar to the equations used by Dube et al. [11]:

$$
\dot{D}_{c}=\left(\frac{<\tilde{\varepsilon}^{e}-\varepsilon_{D 0}-\frac{1}{a_{c}}\left(\frac{D_{c}}{1-D_{c}}\right)^{\left(1 / b_{c}\right)}>}{m_{D_{c}}}\right)^{n_{D_{c}}}
$$

and

$$
\dot{D}_{t}=\left(\frac{<\tilde{\varepsilon}^{e}-\varepsilon_{D 0}-\frac{1}{a_{t}}\left(\frac{D_{t}}{1-D_{t}}\right)^{\left(1 / b_{t}\right)}>}{m_{D_{t}}}\right)^{n_{D_{t}}}
$$

$m_{D_{t}}, n_{D_{t}}, m_{D_{c}}$ and $n_{D_{c}}$ are material parameters which control the rate effect. $a_{c}, a_{t}, b_{c}, b_{t}$ are material parameters which govern the growth of damage in quasistatic tension and compression. $\varepsilon_{D 0}$ is the initial threshold of damage.

Figure 3a shows the response of the damage model in uniaxial tension tests carried out at various strain rates. The response is strongly dependent on the rate of strain, which is in agreement with experiments [1]. Figure 3b shows the response of the damage model in uniaxial compression. We have chosen to have a behaviour in compression which is only slightly dependent on the strain rate. This is again quite consistent with test data. It should be pointed out, however that the model response will be substantially modified in compression, due to the coupling with a viscoplastic model.

On these figures and in all the subsequent computations, the same material is modelled. It is a microconcrete on which many experiments have been performed within an experimental research program of the french network GEO carried out by several French laboratories $[1,14,13,9]$. Its compressive and tensile strengths are $50 \mathrm{MPa}$ and $4 \mathrm{MPa}$ respectively. Its Young's modulus is 23.000 MPa with a Poisson's ratio of 0.17. The same material has been modelled by Le Nard and Bailly [18].

\subsection{Viscoplastic model}

The experiments developed within the French network GEO showed that there was a dependence of the loading rate on the curve relating the volumetric strain to the hydrostatic stress [14], in addition 
to permanent plastic strains and to the material compaction which induces an increase of the bulk and shear moduli of the material. It is thus pertinent to implement a viscoplastic model which will be coupled in the next section to the above damage model. In the absence of damage (which will be added later), the stress - elastic strain relation is:

$$
\sigma_{i j}=\left[K \varepsilon_{k k}^{e} \delta_{i j}+2 G\left(\varepsilon_{i j}^{e}-\frac{1}{3} \varepsilon_{k k}^{e} \delta_{i j}\right)\right]
$$

and

$$
\dot{\varepsilon}_{i j}=\dot{\varepsilon}_{i j}^{e}+\dot{\varepsilon}_{i j}^{v p}
$$

where $\dot{\varepsilon}_{i j}^{v p}$ is the viscoplastic strain rate.

The shear and bulk moduli are functions of the material porosity denoted as $f^{*}$. It is the ratio of the volume of the voids in concrete divided by the apparent volume of the porous material. These functions are computed using Mori-Tanaka homogenisation technique [23]:

$$
\begin{aligned}
& K=\frac{4 K_{M} G_{M}\left(1-f^{*}\right)}{4 G_{M}+3 K_{M} f^{*}} \\
& G=\frac{G_{M}\left(1-f^{*}\right)}{1+\frac{6 K_{M}+12 G_{M}}{9 K_{M}+8 G_{M}} f^{*}}
\end{aligned}
$$

where $K_{M}$ and $G_{M}$ are the bulk and shear moduli of the material without pores respectively.

The viscoplastic strains are obtained following Perzyna's approach:

$$
\dot{\varepsilon}_{i j}^{v p}=\dot{\lambda} \frac{\partial F_{N T}}{\partial \sigma_{i j}}
$$

$F_{N T}$ is the modified Gurson's yield function proposed by Needleman and Tvergaard [20]:

$$
F_{N T}\left(\sigma_{i j}, \sigma_{M}, f^{*}\right)=\frac{3 J_{2}}{\sigma_{M}^{2}}+2 q_{1} f^{*} \cosh \left(q 2 \frac{I_{1}}{2 \sigma_{M}}\right)-\left(1+\left(q_{3} f^{*}\right)^{2}\right)=0
$$

where $\sigma_{M}$ is the stress in concrete without voids and $q_{1}, q_{2}, q_{3}$ are scalars parameters.

Colantonio and Stainier [8] proposed a similar model in which the definition of the plastic multiplier accounts for the variation of porosity of the material. We follow here the same approach and define the viscoplastic multiplier as :

$$
\dot{\lambda}=\frac{f^{*}}{\left(1-f^{*}\right)}\left\langle\frac{F_{N T}}{m_{v p}}\right\rangle^{n_{v p}}
$$

where $m_{v p}$ and $n_{v p}$ are material parameters. The limiting case where the porosity tends to 1 (material failure) should not be considered because tension or compression damage reaches 1 before it may happen. When the pores are completely closed $\left(f^{*}=0\right)$, the viscoplastic incremental strains vanish.

The principle of maximum plastic work for materials with voids was given by Needleman and Tvergaard [20]:

$$
\sigma_{i j} \mathrm{~d} \varepsilon_{i j}^{p}=\left(1-f^{*}\right) \sigma_{M} \mathrm{~d} \varepsilon_{M}^{p}
$$

where $\varepsilon_{M}^{p}$ is the equivalent irreversible strain in the matrix (concrete without voids and cracks) associated to the equivalent stress $\sigma_{M}$. The relation between the equivalent strain and the equivalent stress in the matrix is elastoplastic, with isotropic work hardening:

$$
\begin{cases}\varepsilon_{M}=\frac{\sigma_{M}}{E} & \text { if } \sigma_{M} \leq \sigma_{y} \\ \varepsilon_{M}=\frac{\sigma_{y}}{E}\left(\frac{\sigma_{M}}{\sigma_{y}}\right)^{n} & \text { if } \sigma_{M}>\sigma_{y}\end{cases}
$$


where $E$ is the elastic modulus of the material without void, $\sigma_{y}$ a yield stress and $n$ the hardening exponent.

The variation of the material porosity $f^{*}$ is controlled by the plastic flow, keeping in mind that in practice the material is always compacted (the porosity always decreases because in tension cracking occurs first). Just like in Ref.[7], we assume that the evolution of the porosity is controlled by the irreversible volumetric strain:

$$
\mathrm{d} f^{*}=k\left(1-f^{*}\right) f^{*} \mathrm{~d} \varepsilon_{k k}^{p}
$$

a parameter $k$ is introduced in order to be able to calibrate the velocity with which porosity is closed. Figure 4 shows a comparison of the hydrostatic responses between static and dynamic simulations and the corresponding experiments taken from Ref. [1].

\subsection{Coupled response of the viscoplastic and rate dependent damage mod- els}

The micromechanical phenomena responsible for damage by shearing or extension are completely different from those corresponding to a collapse of the material porosity. The first one is microcracking in tension and tension-shear, while compaction is due to a crushing of the porous cementitious matrix and it is controlled by the hydrostatic stress in triaxial compression. Therefore, it is natural to separate these two mechanisms, one being represented by the damage variable $D$, the other one being represented by the porosity $f^{*}$. These two mechanical effects are combined in the final relationships which relate the stresses to the elastic strains:

$$
\sigma_{i j}=(1-D)\left[K \varepsilon_{k k}^{e} \delta_{i j}+2 G\left(\varepsilon_{i j}^{e}-\frac{1}{3} \varepsilon_{k k}^{e} \delta_{i j}\right)\right]
$$

where the shear $G$ and bulk moduli $K$ are defined in Eq. (9) by Mori-Tanaka's expressions and damage growth as defined in section 2.1.

In tension, the Gurson's yield function is not activated. Viscoplastic strains do not grow and the model described in paragraph 2.1 is recovered. Conversely, when the loading history is such that the positive equivalent strain is always zero (hydrostatic compression or confined uniaxial compression), we will have only the Gurson's yield surface which is activated and the viscoplastic model described in paragraph 2.2 is recovered.

Figure 5a shows the response of the model for hydrostatic compression followed by hydrostatic tension. We observe a hardening behaviour when the porosity of the material decreases. We see also that during unloading, the modulus of elasticity of material is higher than at the beginning of the loading (this is due to the decrease of porosity). Finally, when tension is reached, the rate dependent damage model is recovered, with the elastic constants $K$ and $G$ which have increased due to compaction. A static loading and a dynamic loading were carried out in order to show the influence the strain rate on the model response. As expected, the material stiffness and strength are lower in statics than in dynamics. Hardening occurs later with a stiffer slope in dynamics too.

With regard to the material behaviour in uniaxial compression, the values of the model parameters (particularly $m_{D_{c}}$ and $\sigma_{y}$ ) provide a behavior which is either coupled or not, in the sense that the viscoplastic criterion and the damage criterion can be activated at the same time or not. Figure 5b shows, in the case of a dynamic loading, a curve where the model parameters are such as in one case the damage criterion is activated only (no irreversible strains) and in the second case the two criteria are activated simultaneously. In the second case, a decrease of stiffness occurs at the same time that incremental viscoplastic strains are non zero. Obviously, the first case is much easier to handle as far 
as calibration is concerned because viscoplasticity is restricted to cases where the material is subjected to compression with a significant amount of confinement.

\subsection{Calibration and numerical implementation}

Overall, the constitutive relations contains two parameters which define the elastic behaviour (the shear and bulk moduli of concrete without voids), five parameters which control the material response in tension (including the damage threshold), four parameters which control damage growth in compression. Four parameters enter in the viscoplastic model and two enter in the equation which governs the variation of porosity, including the initial material porosity (the quantities $q_{1}, q_{2}, q_{3}$ assume fixed values usually, see Ref. [7]). The total number of model parameters might be considered to be quite high. In view of the three mechanisms described by the model and the various rate effects, it seems difficult to arrive at a significantly smaller amount of parameters.

The initial porosity depends on the concrete mix. It is usually in the range of 0.3 . The other model parameters are obtained by fitting the following test data: quasistatic experiments in tension, uniaxial compression and triaxial compression (such as uniaxially confined tests [6, 7]), test data obtained for different strain rates, including scabbing tests, and split hopkinson tests on confined and unconfined specimens [1]. This amounts to a large experimental database to be obtained for the same material, which is available for the microconcrete modelled in the present contribution. Of course, one may use the fact that some model parameters can be identified on separate tests independantly. This is the case of the tension and compression damage evolution laws, and of the viscoplastic part of the model which solely controls the nonlinear response of the material in confined compression, when the elastic equivalent strain is zero (no positive strains). The following general procedure can be implemented: (i) Quasistatic tensile tests and a scabbing test provide the parameters entering in the damage model in tension. (ii) The viscoplastic part of the model is calibrated independantly with the help of compression tests on confined specimens where there is no damage, just viscoplasticity, and the variation of porosity is deduced from loading unloading cycles on such experiments (quasistatic tests). (iii) Finally, uniaxial quasistatic compression tests and split Hopkinson compression tests on unconfined specimens provide the remaining parameters, entering into the evolution law of damage in compression. When viscoplasticity enters in the response of the material in uniaxial compression, the calibration is the same, which is the reason why the parameters of the compression damage evolution laws ought to be determined after those of the viscoplastic part of the model.

The model has been implemented in the finite element code LS-DYNA3D in an explicit format. The objective of the numerical implementation of the model is to be able to calculate the new state of stress at time $t+\Delta t$ knowing the increment of strain $\Delta \varepsilon$ and the state of material at time $t$ as quickly as possible. We have implemented an explicit (Euler forward) integration scheme. All the incremental variables during the time increment $\Delta t$ starting at time $t$ are computed from the state variables evaluated at time $t$. The nonlinear response of the material is obtained by an explicit correction of the elastic prediction at each time steps [7].

It is well known that explicit time integration is not accurate if the time increment is too large (i.e. if the viscoplastic incremental strains, damage or incremental porosity are too high). In the case of rate independent plasticity combined to damage, Burlion et al. [7] have used the same integration scheme. It was observed that in practical cases where the three dimensional finite element mesh is sufficiently fine in order to achieve an accurate description of the irreversible phenomena in the structure, the critical time step due to the explicit integration of the equations of motion is so small that the explicit integration of the constitutive relations is accurate enough. Given the fact that both 
the constitutive relations and the equations of motion are integrated explicitely, error accumulation might occur at these two levels. The balance between the internal, kinetic and dissipated energy is monitored in order to detect such situations. Finally, LS-DYNA3D has an erosion option which can be activated in the course of a numerical simulation in order to remove elements in which failure occurs. This element removal implies a loss of mass which is not very important in our problems. This erosion procedure can, for instance, be indexed on critical values of some internal variables in the model, as we will see further.

\section{NUMERICAL SIMULATIONS}

In the following, we are going to discuss several examples of numerical simulations. The foregoing results have been obtained within the framework of a research sponsored by Thomson Daimler Armements in France. For confidentiality reasons, the numerical values of the model parameters of the constitutive relations cannot be provided. Nevertheless, we will show comparisons between the computations and the experiments in order to illustrate the capabilities of the constitutive relations developed in the previous section. All these computations have been performed with the same set of model parameters since concrete is the same. The main characteristics of this material have been provided in the previous section. More comprehensive test data can be found in Ref. [1], and for the sake of comparison, an attempt of modelling the same material with a different constitutive relation can be found in Ref. [18].

\subsection{Dynamic confined compression tests}

Dynamic compression tests have been performed by Gary and co-workers [13] on concrete cylinders of length $40 \mathrm{~mm}$ and diameter $30 \mathrm{~mm}$ confined by a metallic ring (Fig. 6). Hopkinson bars have been used in order to apply on the specimens several strain rates. A sample is placed between two long identical bars (length $6 \mathrm{~m}$ ) with high elastic limit (here $1000 \mathrm{MPa}$ ) compared to that of material tested (Fig. 7). With a striker, a longitudinal compressive wave is generated in the input bar. Part of this wave is reflected on the interface bar-sample, another part transmitted to the sample, and then in the output bar. Strain gauges glued on the two bars record the signals associated with these three waves. In the assumption of a unidimensional wave propagation, strain, stress and particulate velocities applied to the specimen are linearly related. The experimental velocities and forces (along the cylinder axis) applied on the two faces of the concrete specimen are computed.

In the present experiment, the metallic ring is made of steel [14]. The steel ring controls the radial deformation of the specimen and therefore applies a confinement stress on concrete which avoids splitting. The friction between the concrete sample and the metallic ring has been neglected because, experimentally the contact surface is coated with Teflon. Figure 10 shows the 3D finite element mesh used in the computations. It is made of 8 nodded finite elements with a single integration point. The biggest disadvantage of the one-point integration is the need to control the zero energy modes, called hourglassing modes, which arise. Undesirable hourglass modes tend to have periods that are typically much shorter than the periods of the structural response, and they are often observed to be oscillatory. The method used in LS-DYNA3D is the Flanagan-Belytschko approach [15]. It is used throughout the computations presented in this paper. The input and output bars are not represented in the finite element model. Only the confined concrete specimen is described with special boundary conditions which account for wave transmission and reflection. In the simulations, the input and 
output experimental velocities are prescribed to the confined concrete specimen and numerical results of the input and output forces are compared with experimental data.

It should be stressed that the model has been calibrated in compression with the help of the same experiments. The interpretation of the test data differs only. For the calibration, the longitudinal strains and stresses in concrete are calculated with the formulae employed classically for the uniaxial interpretation of the split Hopkinson tests. The difference between the input and output velocities divided by the specimen length provides the average longitudinal strain rate and the stress is computed from the average of the input and output forces. The confinement pressure is computed from the transverse strain on the outer part of the steel ring, assuming it remains elastic. The results obtained from the three dimensional computation are just a validation of the data interpretation and model calibration.

Figure 8 shows the input and output velocities at the specimen boundaries when the striker hits the hopkinson bar at a speed of $6 \mathrm{~m} / \mathrm{s}$. Figure 9 a shows the comparison between the experimental and computed output forces. We have reported also on this figure a similar comparison in the case where the striker speed is $20 \mathrm{~m} / \mathrm{s}$ (Fig. 9b). The good agreement between the experiments and the computation had to be expected since the model has been calibrated using these tests results among others. On these figures, results obtained with the rate independent model devised by Burlion et al. [7] have also been reported. The comparison shows that the rate independent model does not provide accurate results as the speed of the striker, e.g. the strain rate in concrete, is increased. However, the present solution deviates from the experiment with progressing time, due to an overestimation of the reduction of the material porosity.

\subsection{Dynamic tension test}

A tension test by scabbing was performed by Brara [5]. Fig. 11a shows the principle of the test, similar to the Hopkinson set - up, without the output bar. The entering (impacting) bar has a diameter of $40 \mathrm{~mm}$ and a length of $1 \mathrm{~m}$, while the concrete sample has the same diameter as the entering bar and a length of $120 \mathrm{~mm}$.

The finite element mesh used is shown in Fig. 11b. The same finite elements as in the previous computation have been used. The experimental (measured) velocity of the bar end in contact with the concrete specimen is applied to the sample (same as in the previous example). The radial displacement for the impacted surface is blocked, while the other boundaries conditions are free. In the course of the calculation, a crack should occur in the specimen, upon waves reflection at the free end of the concrete specimen and interaction. In the experiment, a single crack at the distance $X=66 \mathrm{~mm}$ approximately from the impacted face was obtained.

Fig. 12a shows the state of stress obtained during the numerical simulations. We obtain a homogeneous state of stress in a vertical cross section of the specimen. Figure $12 \mathrm{~b}$ shows the state of damage associated with this state of stress. When it is subjected to compression $\left(t=4,8.10^{-5} s\right)$ the transverse strains imposed by the boundary condition are not sufficiently high to damage the material. In other words, the damage criterion is not activated. When the compression wave is reflected on the free (opposite) surface of the specimen, it becomes a tensile wave and the strains can become sufficiently large (at time $t=7,2 \cdot 10^{-5} \mathrm{~s}$ ) so that damage grows suddenly up to 1 in a cross section of the sample. This cross section, which represents the place where a macrocrack propagated, is located at a distance ranging between 64 and $69 \mathrm{~mm}$ far from the impacted face. This prediction is in good agreement with the experimental data.

In order to complement the model, erosion can be added as a function of the state of damage: an 
element is removed if the value of the damage variable $D$ at its gauss point is greater than a fixed limit value (note that the elements used possess only a single integration point). Fig. 13 shows the result of simulations when the criterion of erosion is activated. If the criterion of erosion is based on a relatively low value of the damage $\left(D_{1}\right)$, the rupture obtained is very diffuse because many elements will be removed in the course of the damage process. Conversely, if the criterion of erosion on $\mathrm{D}$ is too high $\left(D_{3}\right)$, very few elements will be removed. Fig. 14 shows the evolution of the velocity of the free face versus time. On this figure we can see that when the criterion of erosion is low, the velocity of ejection of the broken part of the specimen is close to $6,5 \mathrm{~m} / \mathrm{s}$, while if the criterion is equal to high it is approximately equal to $3 \mathrm{~m} / \mathrm{s}$. An experimental measurement the scab speed associated with a rather physical criterion (width of crack equal to twice the diameter of the coarsest aggregate approximately), would make it possible to obtain a realistic value of the criterion of erosion.

\subsection{Simulation of an explosion}

In order to evaluate the proposed model on a case more representative of a real application, a test where an explosive is placed in contact with a concrete slab was carried out [1]. For the sake of simplicity, the explosive as well as the concrete slab were axisymmetric. The circular concrete slab had a diameter of 1 meter and a thickness of $20 \mathrm{~cm}$ (Fig. 15). These dimensions were such that the boundary conditions at the edge of the concrete slab did not influence the loading process, as the wave generated by the explosive travelled back and forth through the thickness of the slab. This test was instrumented by strain and pressure gauges embedded in concrete. Fig. 15 and Fig. 16 show the location of the gauges, the P2 plane corresponding to the mid-thickness of the slab.

Figure 16 shows also the mesh used for the numerical simulations. The concrete slab is separated in three distinct parts in order to be able to refine the mesh on the level of the contact between the explosive and concrete. It is a 2D mesh, essentially for computational speed reasons, compared to a full 3D mesh (note that as axisymmetric mesh could have been used as well). The displacements perpendicular to the plane containing the finite element mesh are blocked. This condition represents the symmetry of revolution approximately. It should be pointed out that many problems were encountered in the numerical representation of the contact between the concrete slab and the explosive. A way of limiting these problems was to increase the number of element describing this contact significantly. This is the reason why a full 3D computation is not presented.

The equation of state used to model the detonation in the explosive is of the JWL type, which defines the pressure $p$ induced by the explosion as:

$$
p=A\left(1-\frac{\omega}{R_{1} V}\right) \exp \left(-R_{1} V\right)+B\left(1-\frac{\omega}{R_{2} V}\right) \exp \left(-R_{2} V\right)+\frac{\omega E}{V}
$$

where $A, B, R_{1}, R_{2}, \omega$ are material parameters, $E, V$ represent the internal energy and the volume of the explosive, respectively. The numerical values are given in table 1 . Detonation starts at the center of the explosive. It generates a pressure wave which is transmitted to the slab through the contact conditions in between the two materials.

Fig. 17 shows the evolution of the damage during the calculation. In this calculation, the criterion of erosion was also activated in order to visualise the scab which might be ejected from the back face of the slab. Although a significant mesh effect was observed at the interfaces between the regions of the finite element model where the element density is changed abruptly, the computed size of the scab is: diameter $=26 \mathrm{~cm}$, depth $=4 \mathrm{~cm}$. This is quite close to the experimental values measured on the slabs equipped with the embedded strain gauges. 
Fig. 18 shows the evolution of axial stress versus to time for planes $P 1, P 2$ and $P 3$. We can see that the model is also able to capture quite well the velocity and amplitude of the compression wave within the thickness of the slab.

\section{CONCLUSIONS}

A constitutive relation aimed at describing the response of concrete in dynamics has been presented. It contains a description of microcraking in tension and compression, and of compaction due to hydrostatic compression. The model combines viscoplasticity with a rate dependent damage model. Compaction is described with a homogenisation technique, assuming that concrete is a homogeneous material with voids.

Several conclusions have been obtained from the computations :

- The comparison of the results of the Hopkinson tests on confined specimens reveal that rate effects on the volumetric strain versus hydrostatic compression curve are needed in order to achieve a good description of the tests, at different strain rates.

- The finite element computation of the tensile test shows that scabbing can be well captured with the model. A technique of finite element removal at failure indexed on the state of damage of the material has been implemented (note that this technique is standard in the computer code which we used, only the criterion of erosion is left to be defined by the user).

- The prediction of the response of a concrete slab subjected to an explosion is quite consistent with the experiments, which lends some confidence in the capabilities of the proposed model at describing, with a sufficient amount of details, the response of concrete structures subjected to explosions and impacts.

As a final remark, it ought to be noted that the present approach does not account for the presence of interstitial water in concrete. The model has been calibrated with test data on the material not saturated with water (Humidity $\approx 60 \%$ ). The influence of water should be expected on compaction and on the rate effect.

Acknowledgements : Financial support from Thomson Daimler Armements and the french network GEO is gratefully acknowledged.

\section{References}

[1] Bailly P., "Rapport final, première partie, expérimentation", Comportement des ouvrages en dynamique rapide-Comportement dynamique du béton, Reseau de laboratoire GEO, ENI Bourges, France (1999).

[2] Bazant Z.P., Bishop F.C., and Chang T.P.,"Confined Compression tests of Cement Paste and Concrete up to $300 \mathrm{Ksi",}$ ACI Journal, 33, 553-560 (1986).

[3] Bazant Z.P., Caner, Carol I., Adley M. and Akers, "Microplane Model M4 for Concrete: I Formulation with Work-Conjugate Deviatoric Stress", J. of Engrg. Mech. ASCE, 126, 944-954 (2000).

[4] Bischoff P.H. and Perry S.H., "Compressive Behaviour of Concrete at High Strain Rates", Materials and Structures, 24, 425-450 (1991). 
[5] Brara A. and Klepaczko J.R., "Nouveau dispositif expérimental d'étude de la rupture par écaillage du béton", Communication-Congrès GEO, Aussois, France (1997).

[6] Burlion N., Pijaudier-Cabot G., and Dahan N., "Experimental Analysis of Compaction of Concrete and Mortar", Int. J. Cohesive Frictional Materials, in press.

[7] Burlion N., Gatuingt F., Pijaudier-Cabot G. and Daudeville L., "Compaction and tensile damage in concrete: constitutive modelling and application to dynamics", Computer Methods in Applied Mechanics and Engineering, 183, 291-308 (2000).

[8] Colantonio L. and Stainier L., "Numerical Integration of Visoplastic Constitutive Equations for Porous Materials", Numerical Methods in Engineering, J.-A. Desideri, P. Le Tallec, E. Onate, J. Periaux, and E. Stein, Wiley Pubs, 28-34 (1996).

[9] Darve F., Hicher P.Y., and Reynouard J.-M., Mecanique des geomateriaux, Hermes Pub., 78-102 (1995).

[10] Donze F., Magnier S.A., and Daudeville L., "Study of the Behavior of Concrete at High Strain Rate Compressions by a Discrete Element Method", J. of Engrg. Mech. ASCE, 125, 1154-1163 (1999).

[11] Dube J.F., Pijaudier-Cabot G., and La Borderie C., "A Rate Dependent Damage Model for Concrete in Dynamics", J. of Engrg. Mech ASCE, 122, 939-947 (1996).

[12] Feenstra P.H.," Computational Aspects of Biaxial Stress in Plain and Reinforced Concrete",Doct. Dissertation, Delft University of Technology, The Netherlands, (1993).

[13] Gary G., Bailly P., Gatuingt F., "Testing concrete at high strains and high rates of strain", Impact response of Materials and Structures, Proc. 3rd International Symposium on Impact Engineering'98, Singapore-Japan, 241-246, (1998).

[14] Gatuingt F., "Prévision de la rupture des ouvrages en béton sollicités en dynamique rapide", Thèse de doctorat de l'ENS de Cachan, Cachan, France (1999).

[15] Flanagan D.P. and Belyschko "A uniform strain hexahedron and quadrilateral and orthogonal hourglass control", Int. J. Numer. Meth. Eng. , 17, 679-706, (1981).

[16] Hallquist J.O.,"LS-DYNA 3D -Theoretical Manual", Livermore Software Technology Corporation, Livermore, USA, (1995).

[17] Kennedy, R.P., "A review of procedures for the analysis and design of concrete strutures to resist missile impact effects", Nuclear Engineering and Design, 37, 183-203 (1976).

[18] Le Nard H. and Bailly P., "Dynamic Behaviour of Concrete: the Structural Effect of Compressive Strength Increase", Int. J. Cohesive Frictional Mats.,5, 491-510 (2000).

[19] Lubarda V.A., Mastilovic S. and Knap J., "Brittle-Ductile transition in porous Rock by Cap Model", J. of Engrg. Mech. ASCE, 122, (1996).

[20] Needleman A. and Tvergaard V., "An analysis of ductile rupture in notched bars", Journal of Physics and mechanics of Solids, 32, 461-490 (1984). 
[21] Mazars J., Application de la mecanique de l'endommagement au comportement non lineaire et a la rupture du beton de structure, These de Doctorat d'Etat, Universite Paris 6, Paris, France (1984).

[22] Mazars J., "A description of micro and macroscale damage of concrete structures", Journal Engineering Fracture of Mechanics, 25, 729-737 (1986).

[23] Mori T. and Tanaka K., "Average stress in matrix and elastic energy of materials with misfitting inclusions", Acta Metallurgica, 21, 571-574 (1973).

[24] Simo J.C. and Ju J.W., "Strain and Stress Based Continuum Damage Models -I Formulation", Int. J. Solids and Structures, 23, 821-840 (1987).

[25] Sluys L.J., Wave Propagation, Localisation and Dispersion in Softening Solids, Doct. Dissertation, Delft University of Technology, The Netherlands, (1992).

[26] Sluys L.J. and de Borst R., "Analysis of Impact Fracture in a Double -Notched Specimen Including Rate Effects", Fracture Mechanics of Concrete Structures, Z.P. Bazant Ed., Elsevier Pub., 610-615 (1992).

[27] Whirley R.G. and Hallquist J.O.,"DYNA3D: A Nonlinear Explicit Three-Dimensional Finite Element Code for Solid and Structural Mechanics", User Manual, Report UCRL-MA-10254, Lawrence Livermore National Laboratory, Livermore, USA, (1991).

[28] Yazdani S. and Schreyer H.L.,"Combined Plasticity and Damage Mechanics Model for Plain Concrete", J. of Engrg. Mech. ASCE, 116, 1435-1450 (1990). 


\begin{tabular}{|c|c|}
\hline$A$ & $9.8968 \mathrm{e} 11$ \\
\hline$B$ & $1.586 \mathrm{e} 10$ \\
\hline$R_{1}$ & 4.72 \\
\hline$R_{2}$ & 1.0 \\
\hline$\omega$ & 0.4 \\
\hline$E_{0}$ & 0.0 \\
\hline
\end{tabular}

Table 1: Parameters of the JWL law for the explosive. 

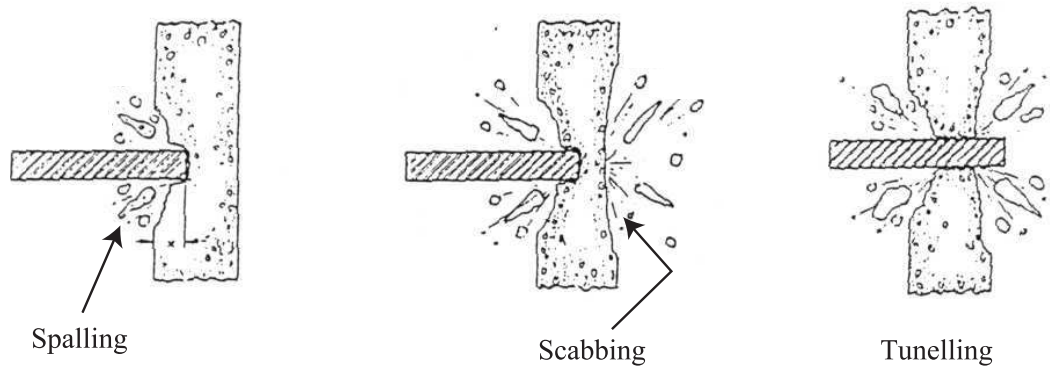

Figure 1: Schematic case of an impact on a concrete slab, after Ref. [17] 

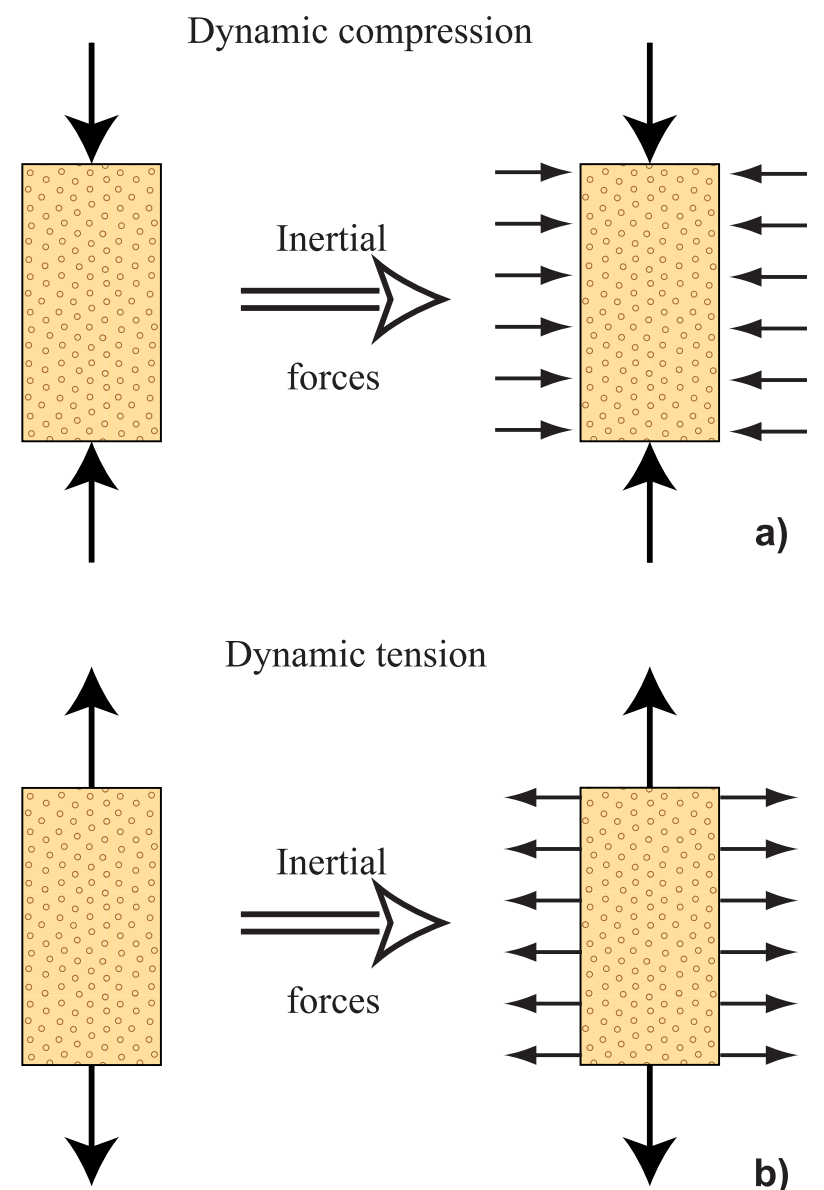

Dynamic tension

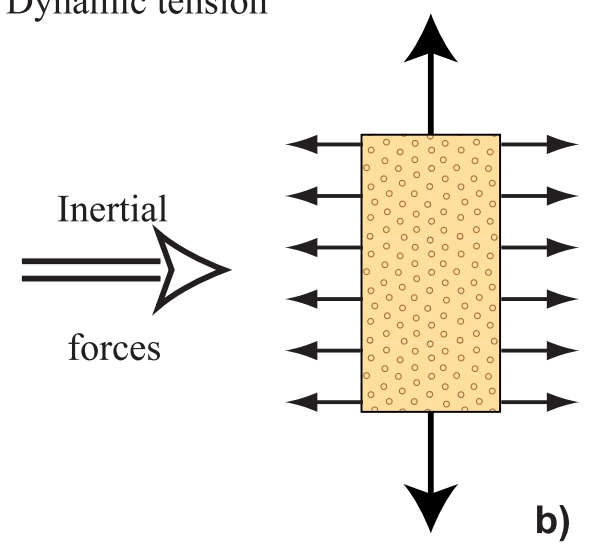

Figure 2: Effect of interial confinement in uniaxial compression (a) and uniaxial tension (b) 

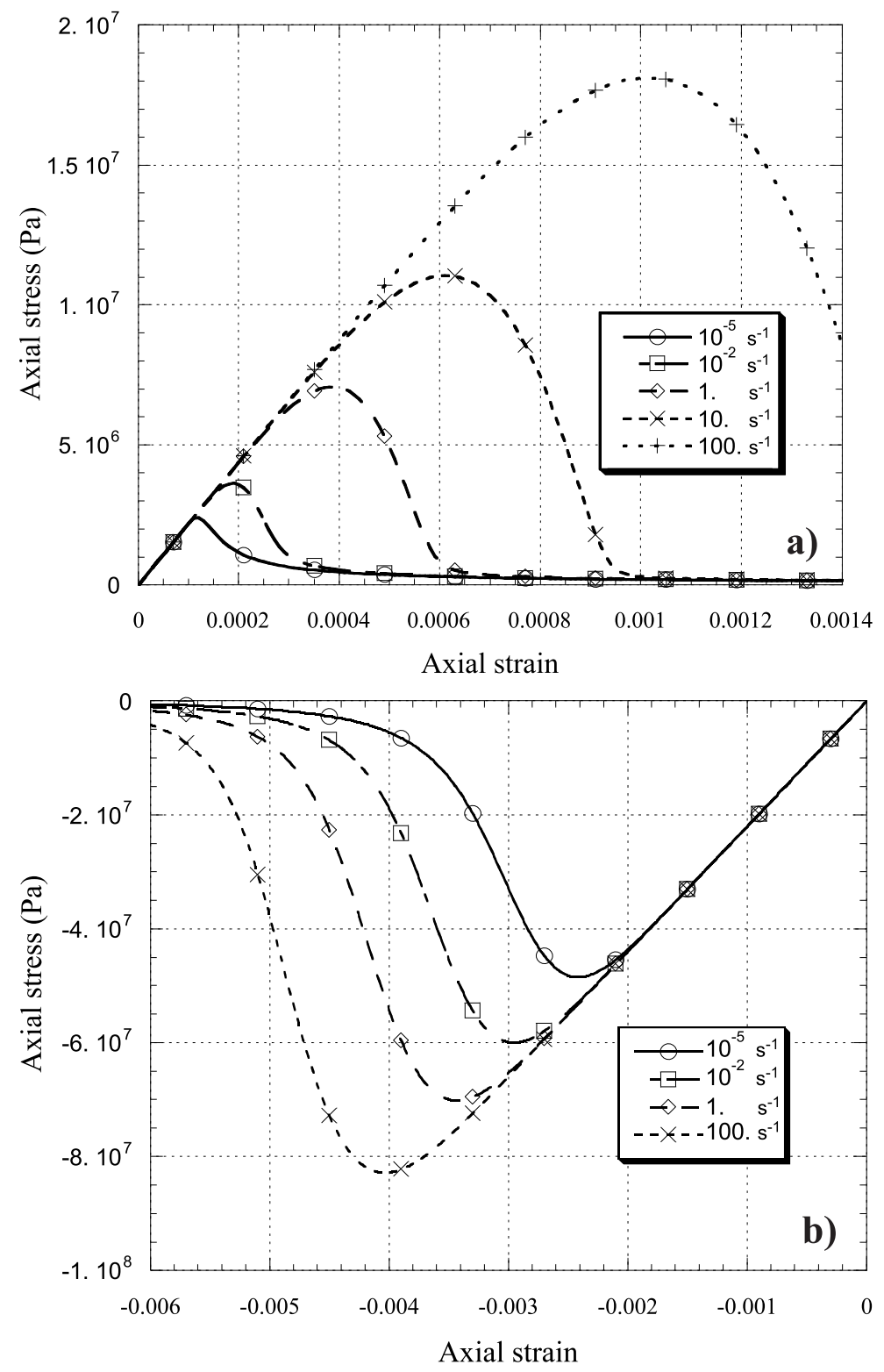

Figure 3: Model response for several strain rate: a) uniaxial tension test, b) uniaxial compression test. 


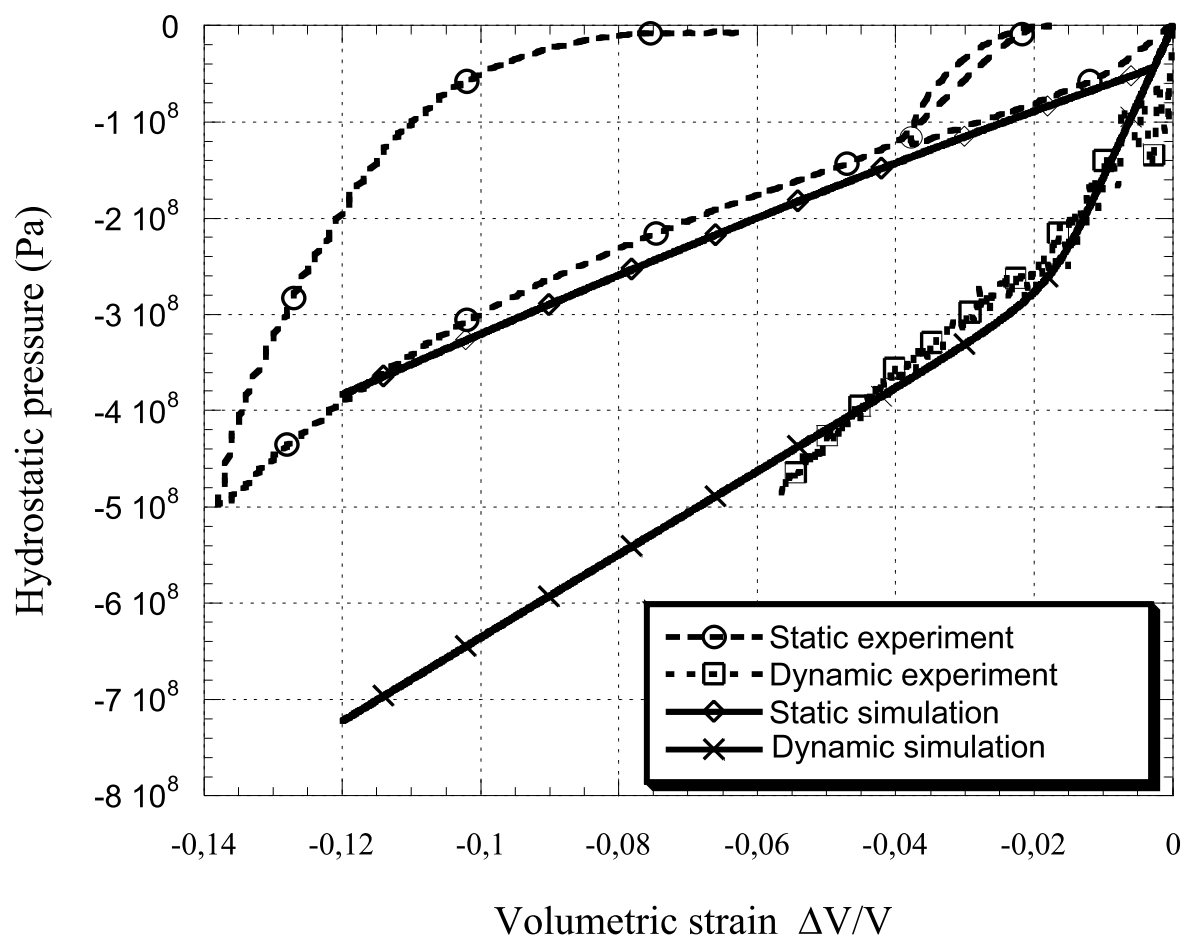

Figure 4: Calibration of the parameter of viscosity on the hydrostatic response of the model. 

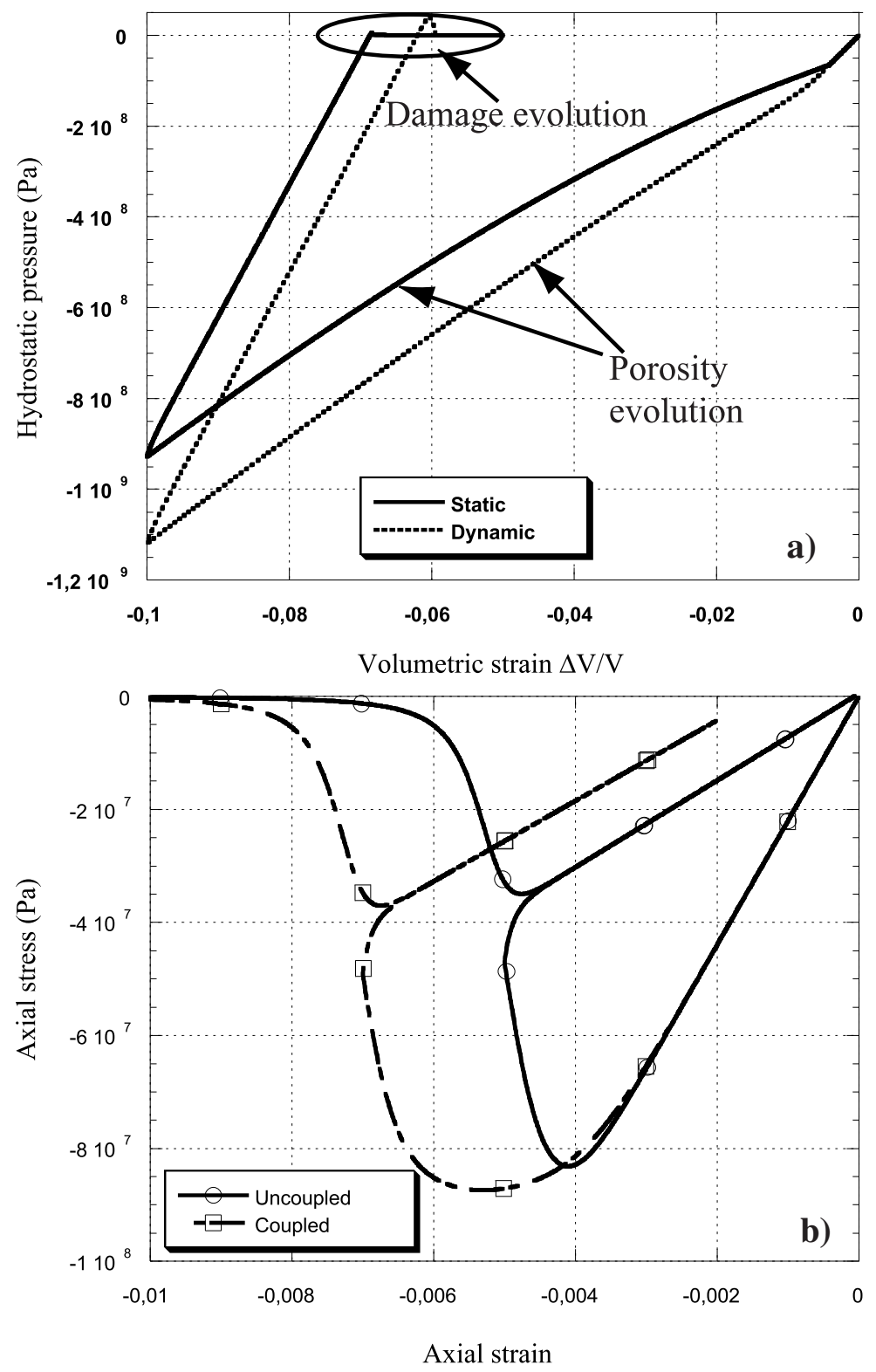

Figure 5: Response of the model coupled in the case of: a) hydrostatic compression followed by hydrostatic tension for a static loading $\left(\dot{\varepsilon}=10^{-5} \mathrm{~s}^{-1}\right)$ and a dynamic loading $\left(\dot{\varepsilon}=1 \mathrm{~s}^{-1}\right)$, b) uniaxial (coupled and uncoupled) compression. 


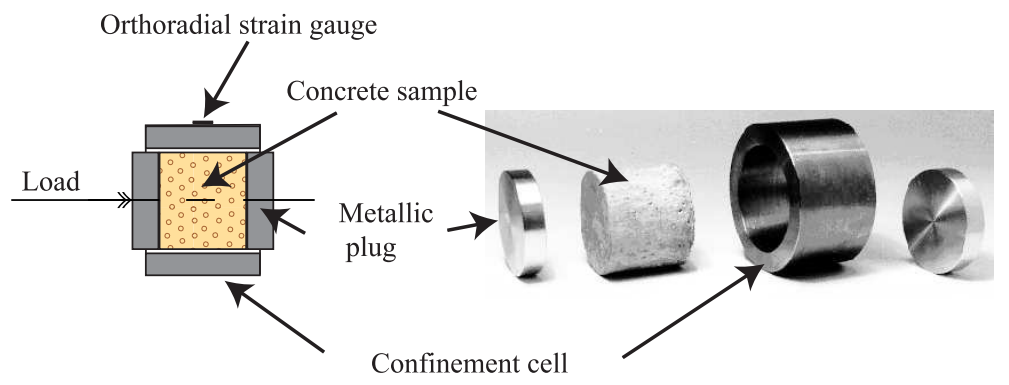

Figure 6: Specimen set-up of the dynamic confined compressions tests

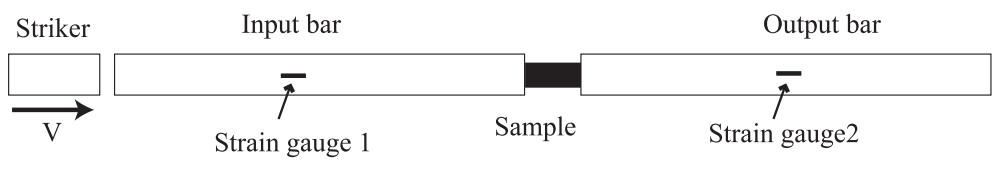

Figure 7: Split Hopkinson pressure bar set-up 


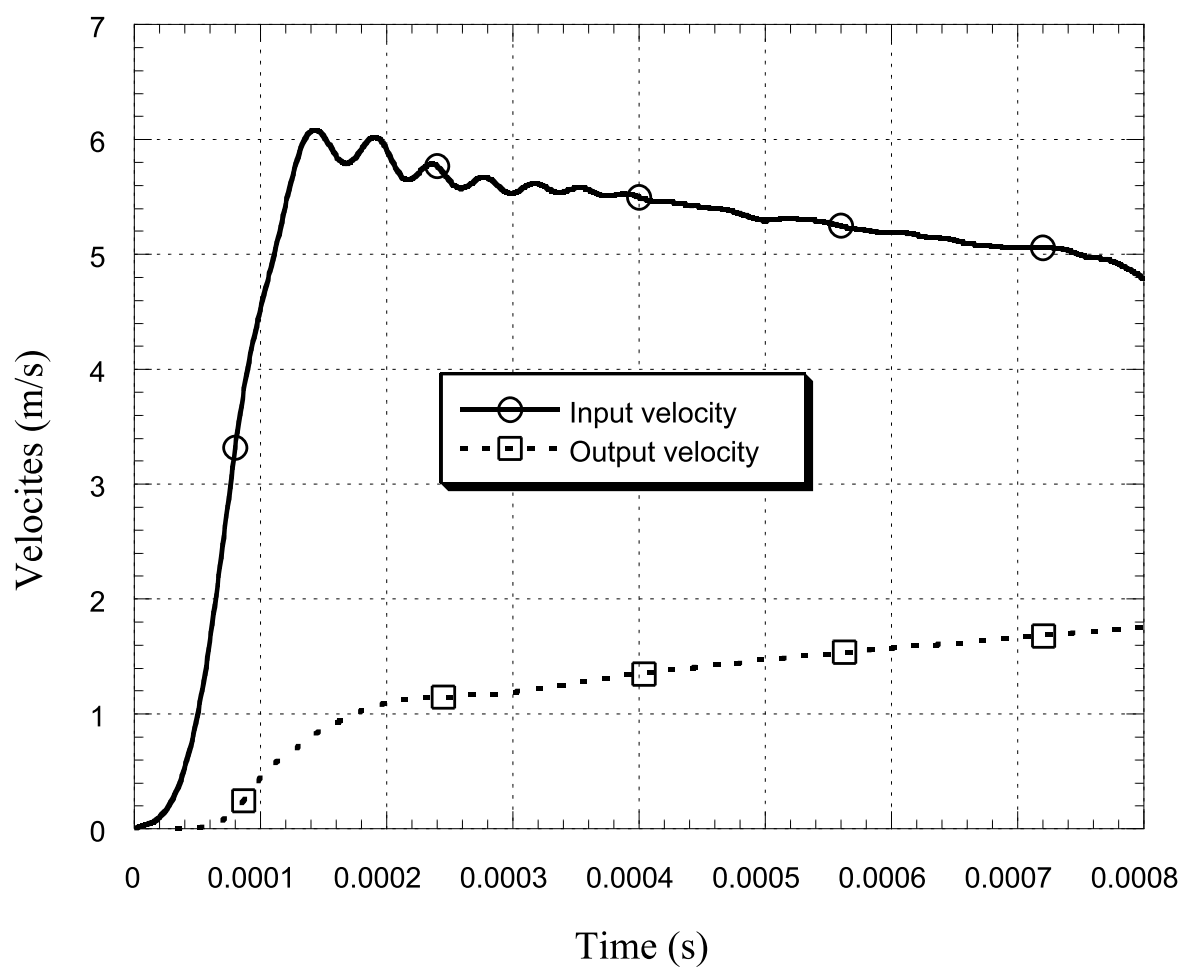

Figure 8: Experimental input and output velocities for a striker at a speed of $6 \mathrm{~m} / \mathrm{s}$ 

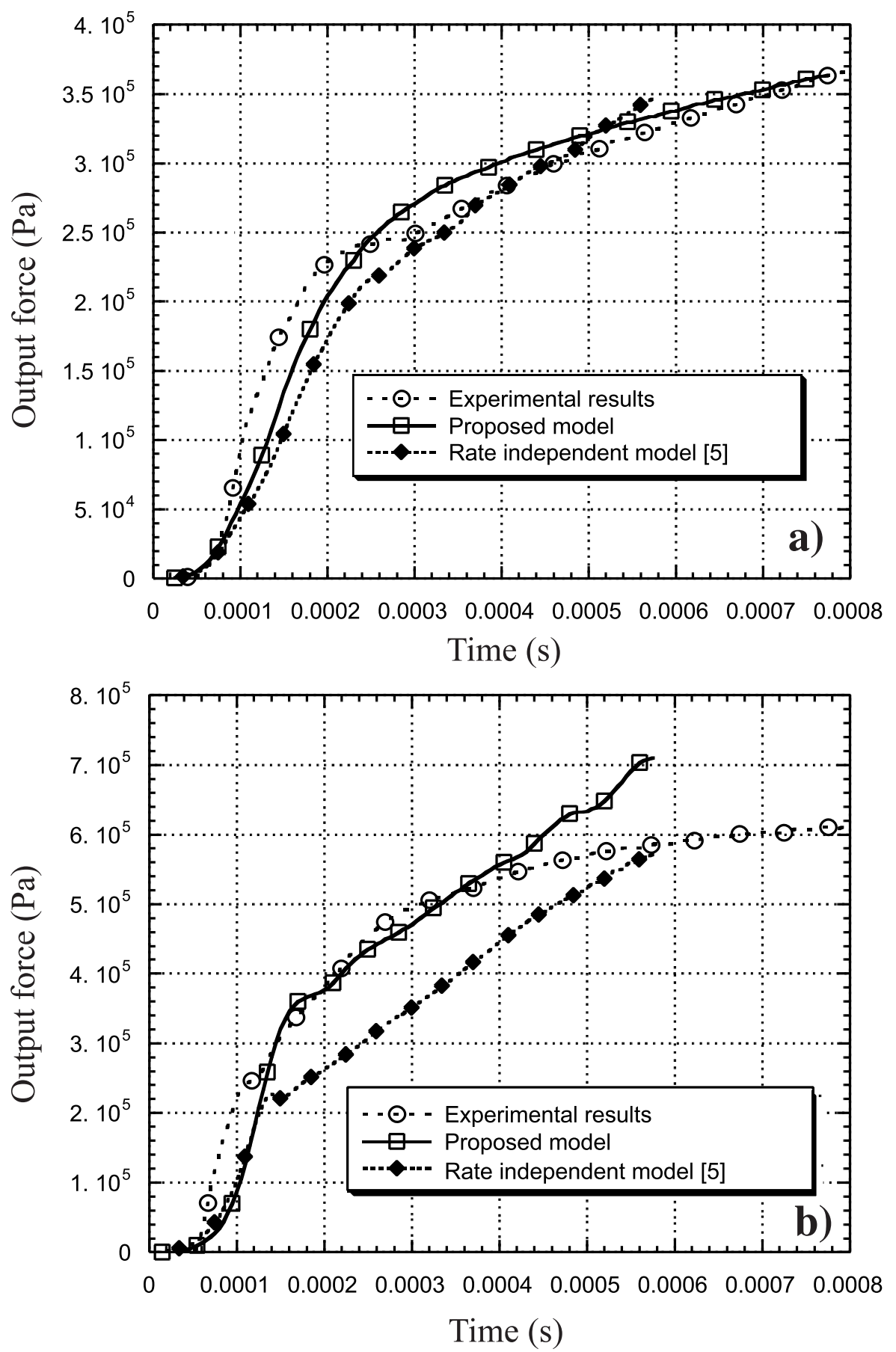

Figure 9: Comparison between experimental and computed output forces: a) striker at a speed of 6 $\mathrm{m} / \mathrm{s}, \mathrm{b})$ striker at a speed of $20 \mathrm{~m} / \mathrm{s}$ 


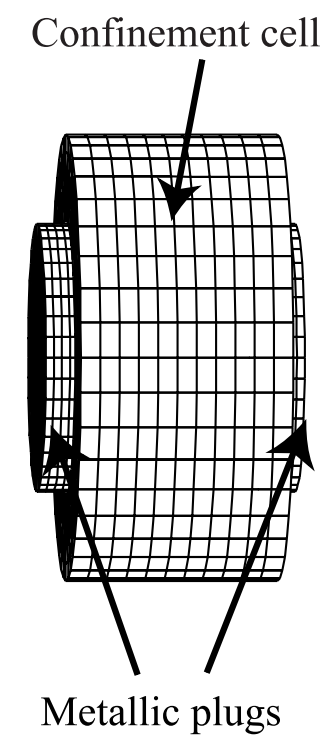

Figure 10: 3D finite element mesh of the confined concrete specimen 


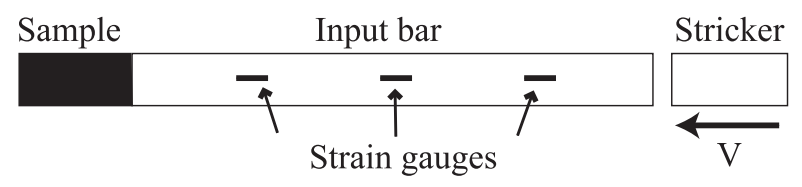

a)

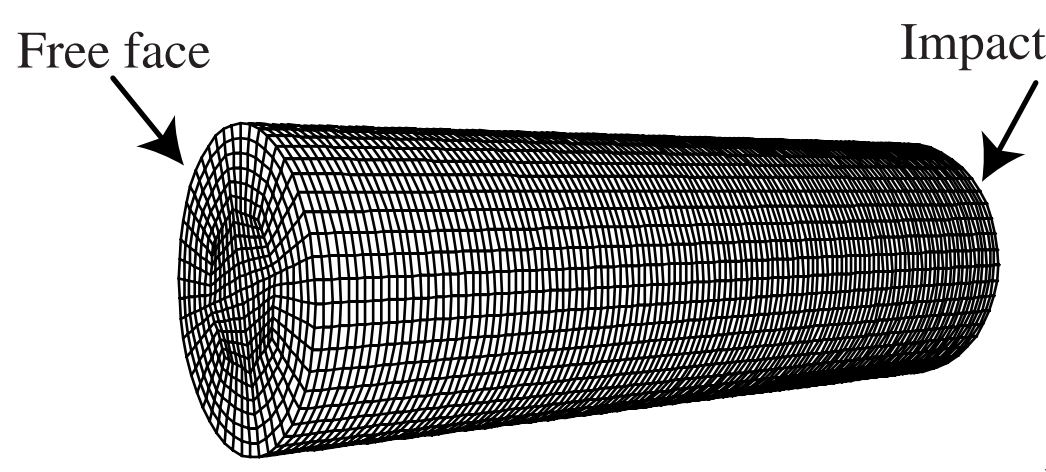

b)

Figure 11: Tension test: a) experimental principle (the sample is glued to the input bar), b) finite element mesh of the concrete sample. 


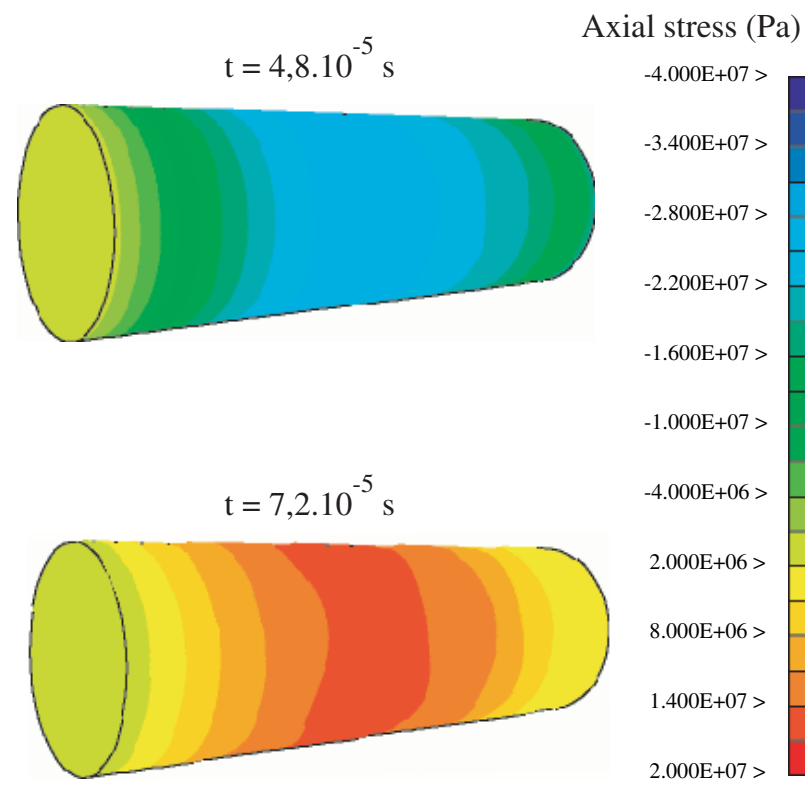

a)

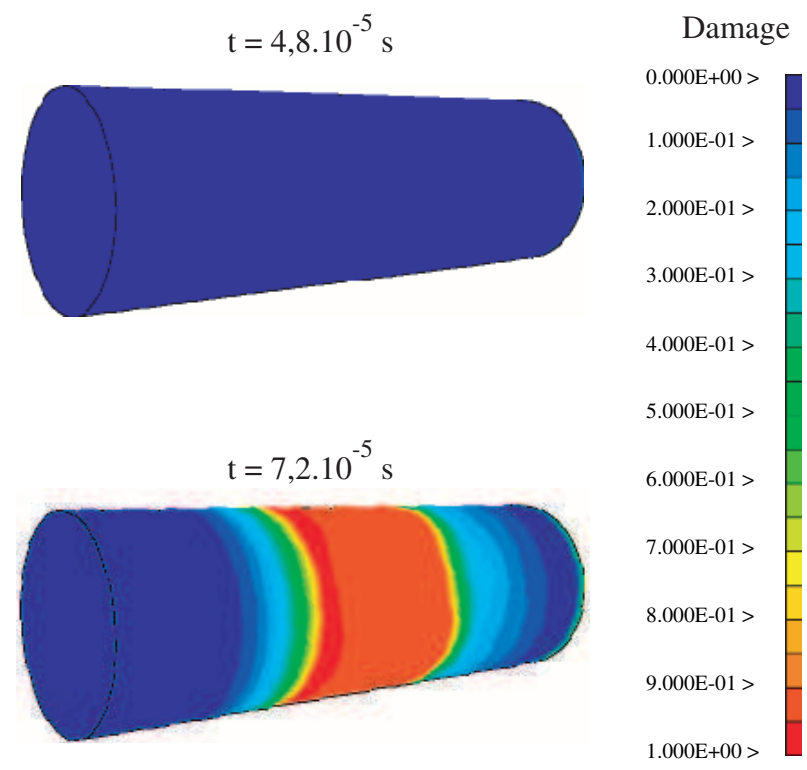

b)

Figure 12: Tensile test: a) stress evolution, b) damage evolution. 

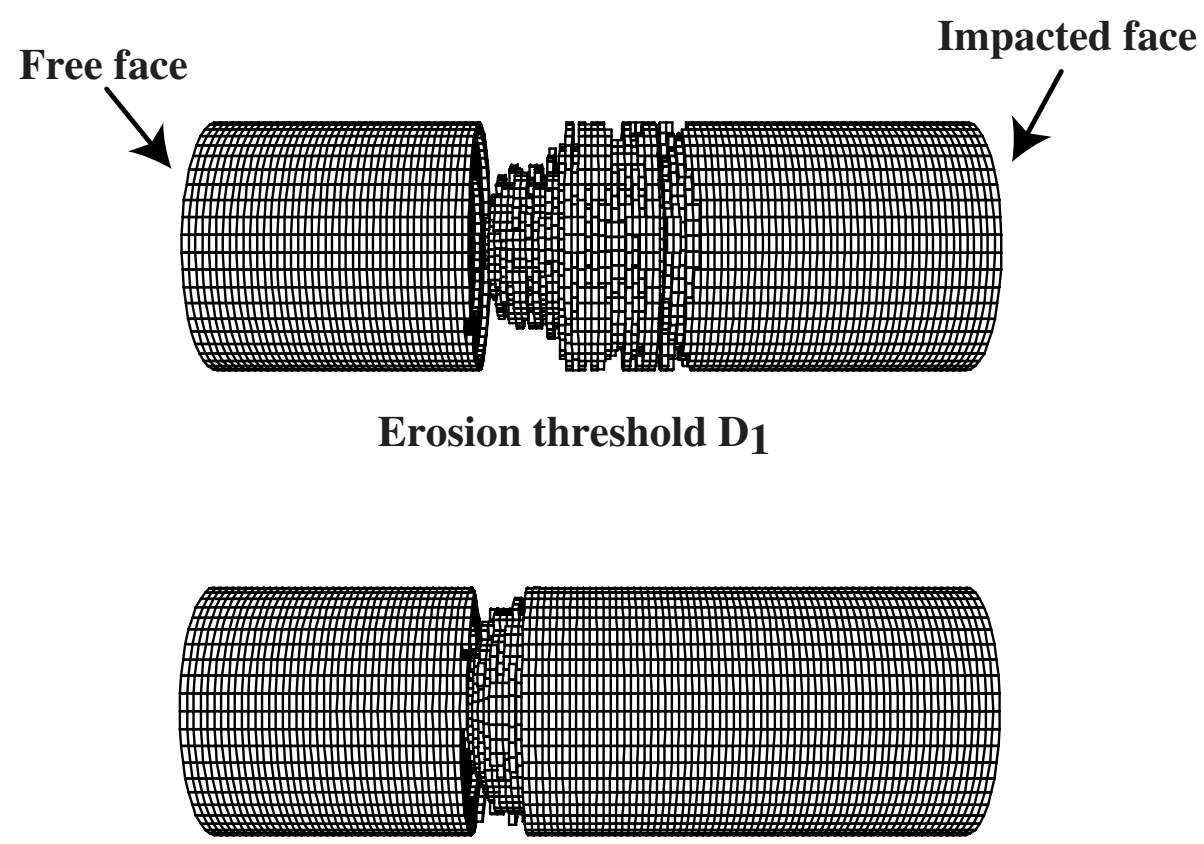

Erosion threshold $\mathrm{D}_{2}$

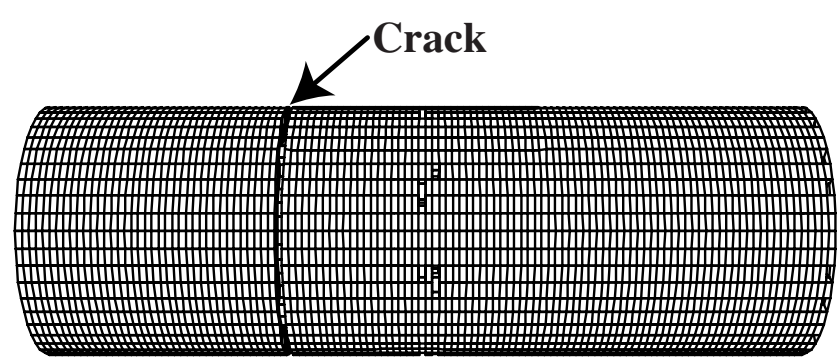

Erosion threshold D3

Figure 13: Element removals at failure for various values of the erosion threshold $D_{1}<D_{2}<D_{3}$. 


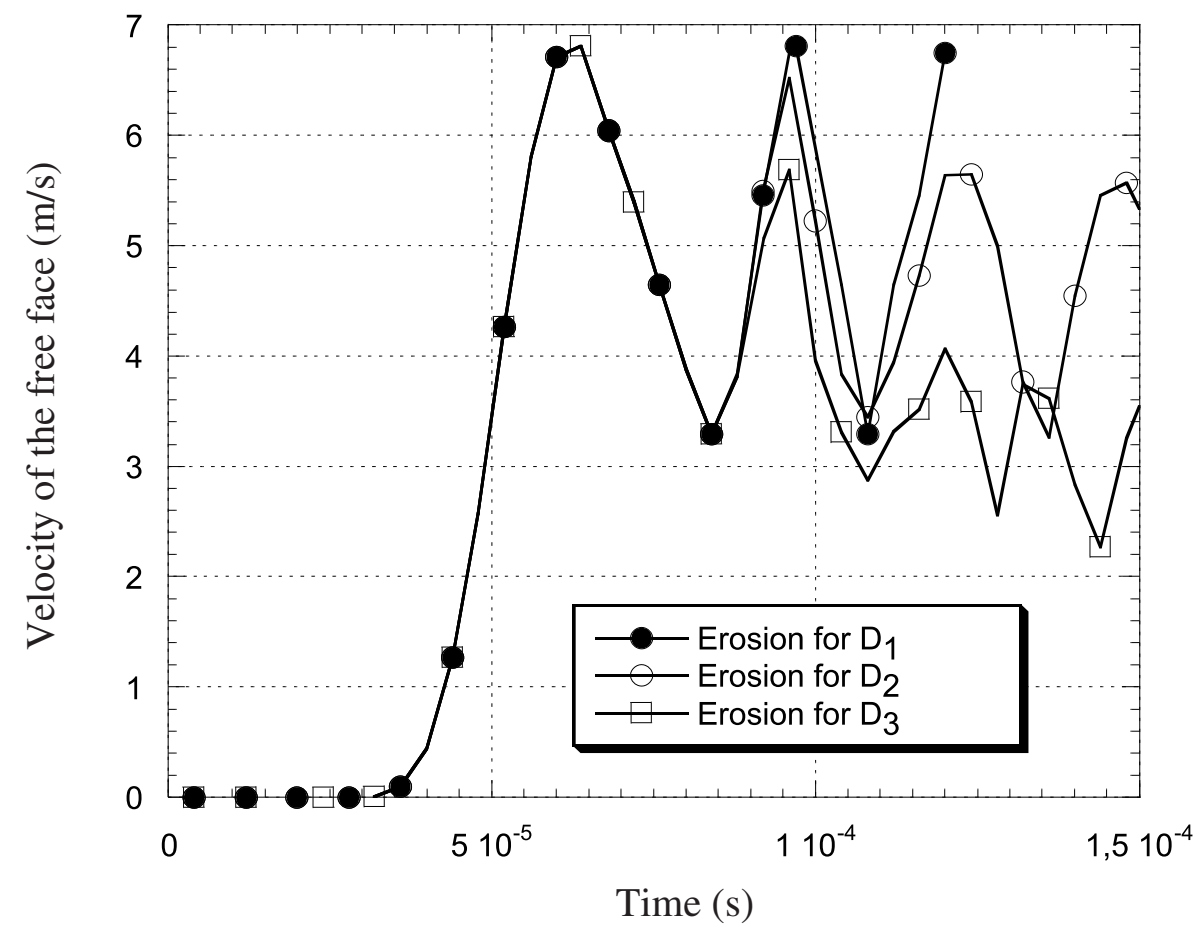

Figure 14: Average velocity of the free end of the specimen for various values of the erosion threshold $D_{1}<D_{2}<D_{3}$. 

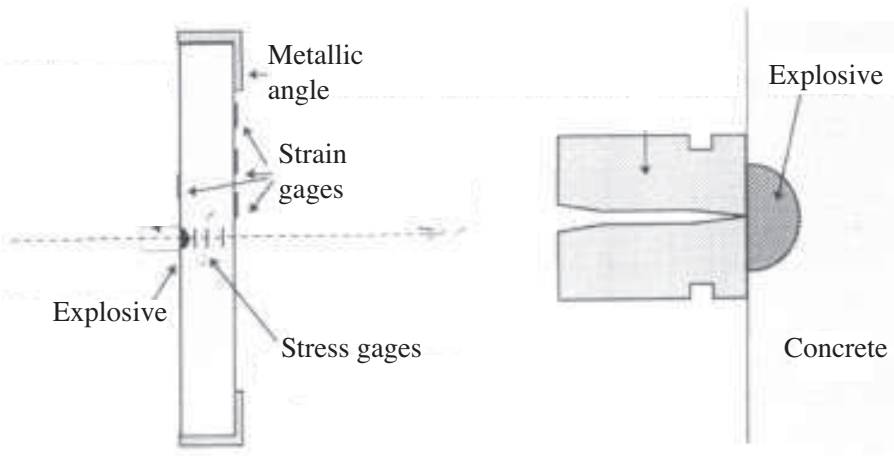

Figure 15: Explosion at the surface of a concrete slab: description of the experimental device. 


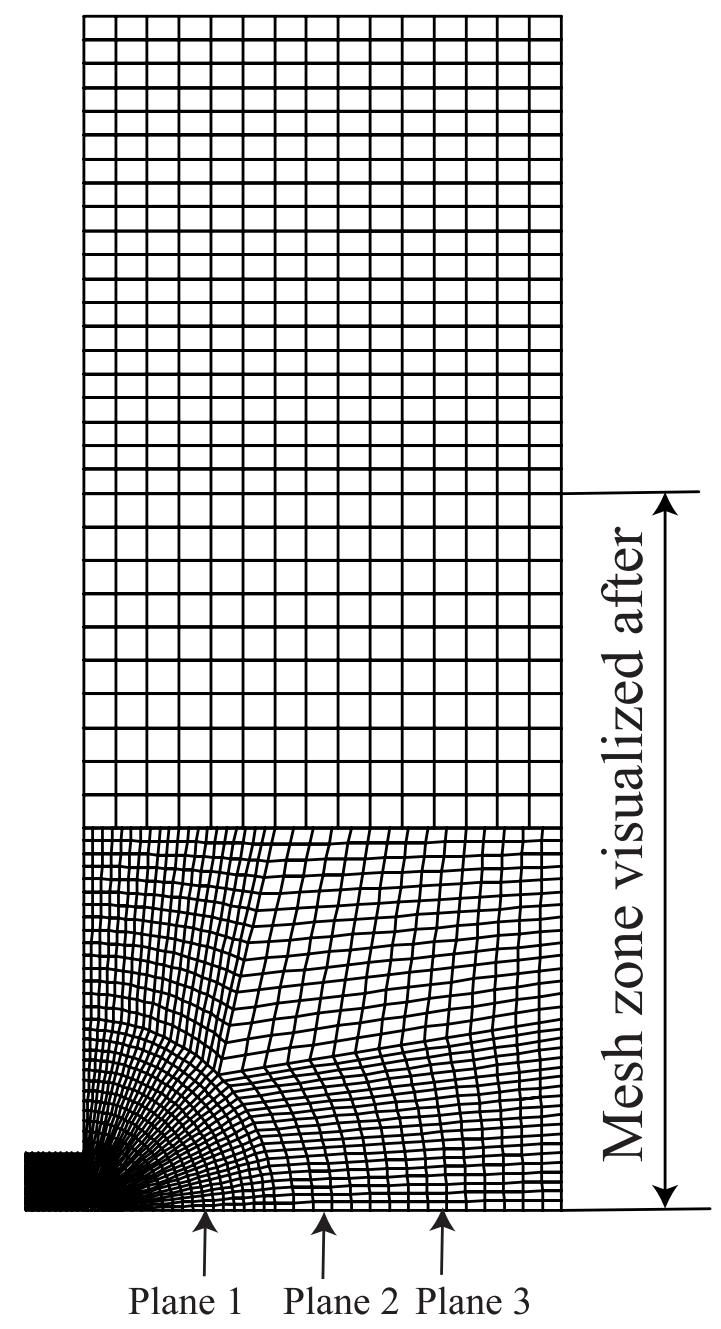

Figure 16: 2D mesh of the slab and explosive. 

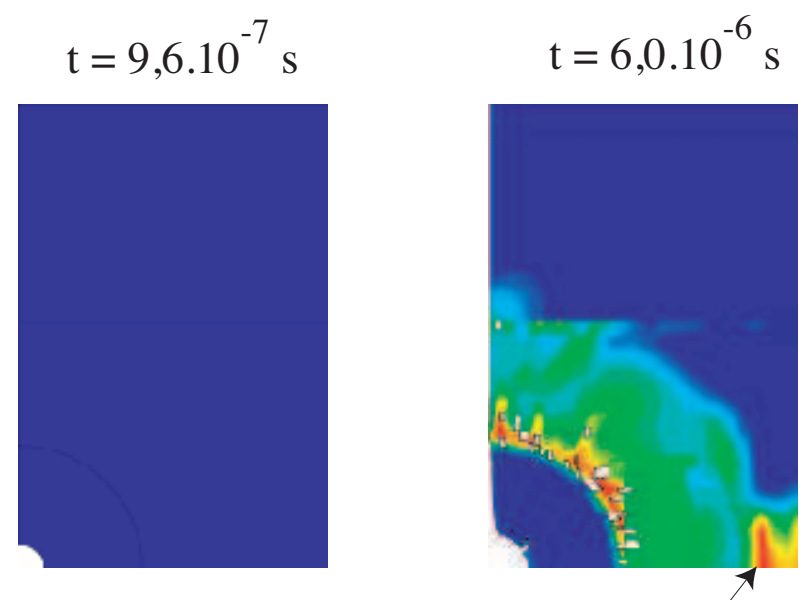

\section{Damage}

$0.000 \mathrm{E}+00>$ $1.000 \mathrm{E}-01>$ 2.000E-01 > 3.000E-01> 4.000E-01 >

\section{Begining of scabbing}
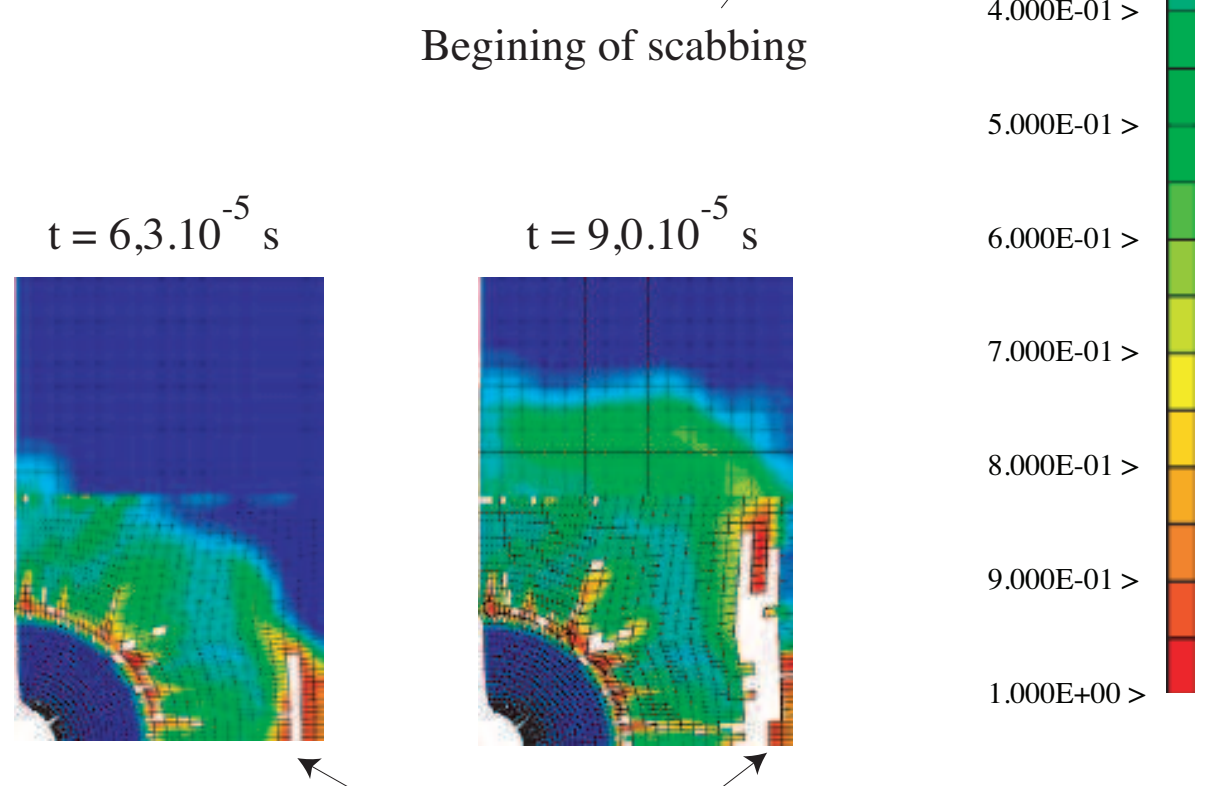

\section{Scabbing}

Figure 17: Evolution of damage. 


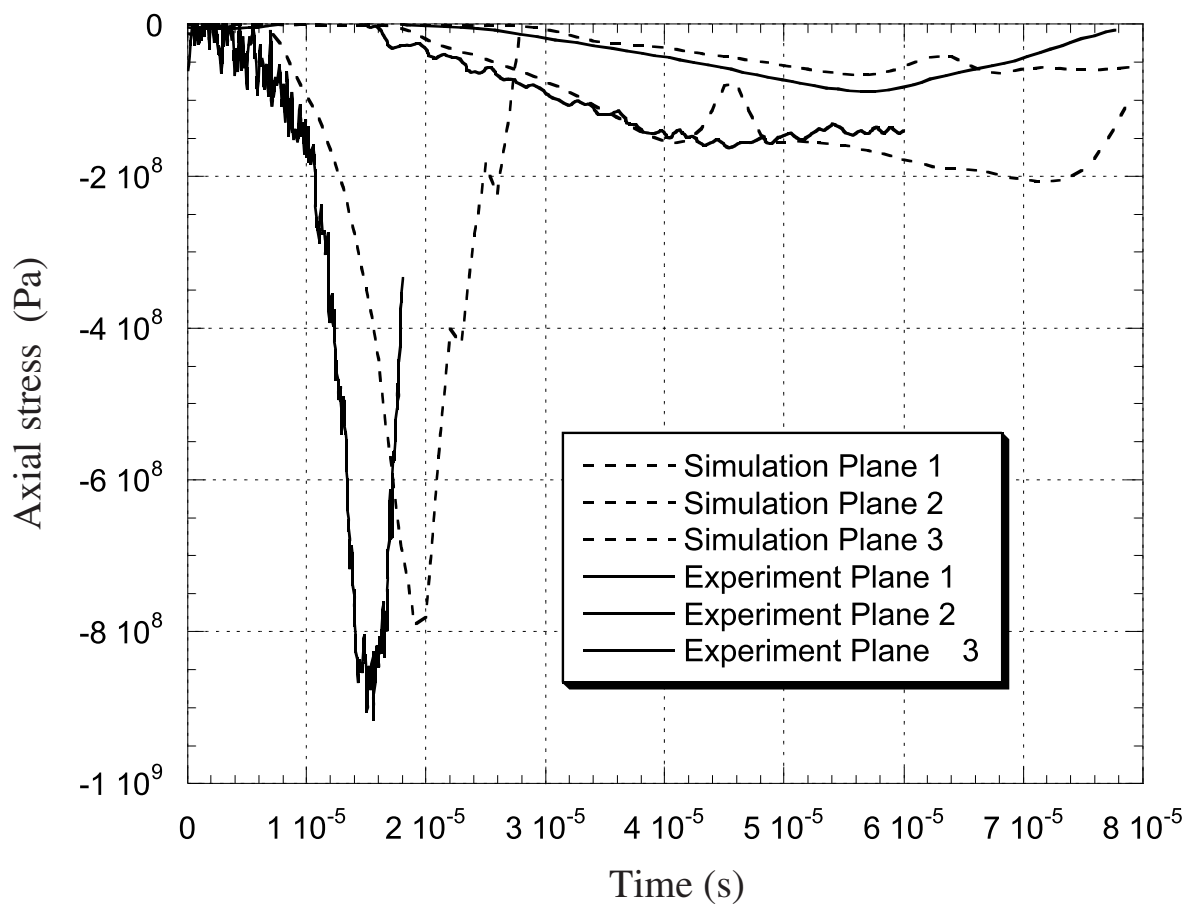

Figure 18: Comparison between the simulation and the experiment: axial stress on the 3 planes versus time. 